\title{
ARABIC IS THE LANGUAGE OF 'AHLUL-JANNAH' (PEOPLE OF PARADISE): THE RELIGIOUS STATUS OF ARABIC LANGUAGE CONTRIBUTES TO ITS MAINTENANCE
}

\author{
Dr. Mostefa Abdelhadi \\ University of Southern Queensland, Australia \\ Email : mostefaabdelhadi@yahoo.com.au
}

\begin{abstract}
This paper attempts to investigate the impact of the religious status of the Arabic language and to find out to what extent this status contributes to its maintenance within the Arabicspeaking community in the regional Queensland city of Toowoomba, Australia. A qualitative approach was employed in order to explore the language maintenance phenomenon through engaging in the everyday life of the Arabic speakers. Data was gathered through participant observations and in-depth semi-structured interviews with 20 adults who were selected using a mixed purposeful sampling strategy. The findings of this study reveal that the Arabic language is maintained among the Arabic speakers due to the high exalted status that Arabic holds as a language of Islam which represents the Arab and Muslim identity. The conclusions of this study are envisaged to enrich the knowledge and theories of language maintenance, as well as redesigning the multilingualism and multiculturalism structure of the Australian society.
\end{abstract}

Keywords: Language Maintenance, Community Language, Language Status, Arabic Language.

\section{Background}

Australia has always been recognized by its linguistic and cultural diversity practised by the Indigenous inhabitants. It is reported that there were more than 600 Aboriginal and Torres Strait Islander languages during the British settlement in Australia (Hatoss, 2013). Unfortunately, most of these languages have disappeared and the number has diminished to only 150 languages, due to the settlers' conflict with the Indigenous people and the early death of indigenous people from epidemic diseases (Holmes, 2013) as well as assimilation pressures (Clyne, 1991). More recently, the linguistic situation in Australia has been entirely amended and reshaped with another 150 immigrant languages, other than English, being brought by immigrants from all over the globe. In spite of such huge linguistic and cultural diversity, with over 300 languages spoken by Indigenous Australians and immigrants, Australia remains a mostly monolingual society where most of the population speaks English as the majority and de facto official language (Beykont, 2010; Holmes, 2013; Rubino, 2010).

On the basis of the 2011 Census of the Australian Bureau of Statistics (ABS), 81\% of the Australian population speak English at home, and this number has decreased slightly from $86 \%$ in 1986 (ABS, 2011).That implies that less than 20\% of people speak their native language at home, and this little number may alert us to the fact that some languages are on the edge of language shift in Australia. Statistics from the same census indicate that: (1) The majority of immigrants are gradually losing their original languages (ABS, 2011); (2) Australia policies are unsuccessful in encouraging the maintenance and transmission of the original language across generations (Hatoss, 2013); and (3) Multiculturalism policies have failed to protect and promote minority languages (Cavallaro, 2005). 
The purpose of this study is to examine the intimate relationship between Arabic and Islam and to identify how the language status may attract the Arabic speakers in the regional city of Toowoomba, Australia to value and maintain their community language.

\section{Literature Review}

The Arabic language is related to the Semitic languages, and it is spoken mainly in its geographical area of the Arabian Peninsula and in North Africa (Versteegh, 2014). In the Arab world, the Arabic language is considered the standard language of the twenty-two Arab countries along with other countries such as Israel, Chad and Eretria (Bateson, 2003). The Arabic language has contributed to the construction of many other languages in the Islamic world, such as Berber, Persian, Turkish, Bosnian, Bengali, Urdu and Hindi (Javed, 2013).

The Arabic language possesses a solid position and a high status among, not only Arabs, but all Muslims worldwide. It has a religious significance as being the language of the Holy Qur'an that was revealed to the Prophet Muhammed. Arabic speakers use different varieties of Arabic. There are two formal varieties of Arabic, known in English as Classical Arabic, and Modern Standard Arabic (MSA) and one informal variety of Arabic called colloquial Arabic (dialect). Firstly, Classical Arabic, is known as the original language of the Qur'an and it was used in the era before Islam (Hijjawi \& Elsheikh, 2015). Classical Arabic is used for religious and ceremonial purposes. Secondly, Modern Standard Arabic derives from Classical Arabic and regarded as a simplified version of it (Owens, 2006). It is also called literary Arabic, which is used in written documents and during formal speaking occasions. Modern Standard Arabic serves as a lingua franca among all Arabs (Carreira \& Kagan, 2011; Rouchdy, 2013). Thirdly, a dialect is the colloquial variety of Arabic and each country has its own dialect that distinguishes it from other varieties (Owens, 2006). According to Benrabah (2004), Arabic dialects are the most commonly spoken languages amongst all Arabs.

\subsection{The status of Arabic Language in the World}

Arabic is the common native language for more than 300 million speakers in the world (Bale, 2010). Most of these speakers live in the Arabic-speaking countries of the Middle East and North Africa (Bale, 2010; Beeston, 2016). It is pointed out by De Swaan(2013) that: "Arabic has reached its zenith as a world language", in which it is among the seven most widely spoken languages in the world (Baker, 2011). Nowadays, the Arabic language is growing quickly with a high number of speakers in the USA, and it is among the six most recognized official spoken languages of the United Nations (Temples, 2013). This international status of the Arabic language makes it highly valued by its speakers and encourages them to maintain it for upcoming generations. As Holmes (2013) argued "the status of a language internationally can contribute to these positive attitudes" (p. 63). In the Australian society, Arabic is employed by several Muslim and Arab communities in their everyday dealings and interactions, as well as for liturgical purposes.

\subsection{The Status of Arabic in Islam}

The status of Arabic is linked with its prestige as being the language of the Qur'an and Islamic teachings (Clyne, 2005; Jamai, 2008). Clyne (2005) pointed to "the symbolic status of Arabic within Islam as the language through which Allah spoke to the Prophet Mohammed and through the Qur'an to His people" (p. 82). Within the Arab states, with a majority of Muslims the Arabic language holds a very high status because of its connection with Muslim beliefs (Holmes, 2013).

In the same context, Rouchdy (2013) refers to the religious status of Arabic as the unique language that is used by all Muslims when they are performing their daily prayers. According to Rouchdy, this religious status of Arabic also represents the religious identity of all Muslims. Hayati and Mashhadi (2010) point out that the Arabic language is taught in Iran alongside the Persian language as the main foreign language to preserve Islamic traditions.

Similarly, Dweik, Nofal \& Qawasmeh (2014), in their investigation of Muslim Arabs in Vancouver, found that all the participants demonstrated positive attitudes towards the 
Arabic language because of its status. The finding revealed that Arabic was considered the most prestigious language among all the participants because of its connection with the Holy Qur'an.

Another study, conducted by Vaish (2008), focused on the impact of religion on language use in Singapore. The results indicated that Malays maintained the Arabic language in their religious practices for its exalted status as the language of the Qur'an. All Malay children learned the Arabic language outside of school because it represented their identity as Malay Muslims and it is the language that can connect them with other Muslims all over the world. Children had positive attitudes towards learning the Arabic language, knowing more about their religion, and reading about the history of Islam.

It is obvious from all these findings that Arabic language is highly valued and esteemed by the Muslim and Arab communities because of its close relationship with Islam as being the language of the Holy Qur'an. So, this religious status that Arabic holds contributes positively to its maintenance among its speakers.

\section{Methodology \\ 3.1 Participants}

In this qualitative study, the sample size was determined by the concept of saturation. The researcher was looking for the factors that may contribute to the maintenance of the Arabic language within the Arabic speaking community in the regional city of Toowoomba. The sample included 20 participants who were drawn purposefully from the community membership list at the Mosque.

A mixed purposeful sampling technique was used for recruiting 20 Arabic speakers from the mosque in the regional city of Toowoomba, Australia to participate in this study. First, the researcher conducted a purposive sampling technique at first in order to select 12 adult male participants from the membership list at the mosque. This list includes the population of about 1000 male adult individuals who are members of the mosque by paying annual membership fees. The Arabic speakers represent the majority at the Mosque.

The selection criteria for participation were: (1) adult first generation Arabic native speaker, (2) Arab in ethnicity, (3) married with at least one child. Second, eight female participants were recruited by a female research assistant using a snowballing technique. In this technique, each participant who agreed voluntarily to participate in this study was asked to identify other participants who met the selection criteria mentioned above and were willing to participate (Johnson \& Christensen, 2012). The snowballing technique was utilized due to the difficulty in finding female participants since they do not regularly come to the mosque. Additionally, there were other constraints such as the religious and cultural concerns among Arabic speakers. In view of that, the researcher was obliged to appoint a female research assistant to recruit, interview and observe female participants.

With respect to their age, the majority are in their 30s; there are only four in their 40 s and two in their late 20s. All the participants came to Australia in the last decade between 2006 and 2013. With regards to education, $90 \%$ of the participants were still students during the time the research was conducted. Among them, 35\% were undertaking Ph.D. studies, $35 \%$ a Master's Degree, 25\% a Bachelor of Arts Degree, and 5\% had a High School Certificate. A larger proportion came to study and subsequently preferred to settle down and live in Australia. However, there were only two male participants who were married to non-Arabicspeaking spouses. Their wives came from English-speaking countries: Australia and New Zealand. 


\subsection{Data Collection Strategies}

Firstly, in order to answer the research questions, data were first gathered using in-depth, semi-structured interviews with the 20 Arabic speakers who met the sample selection criteria discussed in the "Participants" section.

Secondly, in order to learn more about the participants' perspectives and experience, data were collected through observation in which the researcher observes and take field notes from the participants' interaction in order to form a better understanding of the central phenomenon.

\subsection{Ethical Considerations}

Approval for this research was gained from the Human Research Ethics Committee (HREC) at the University of Southern Queensland, Australia. All ethical concerns about all aspects of this research were clearly explained to the participants verbally and it was also included in the participant information sheet, as well as in the consent form. Participants in this study were informed that their contribution was entirely voluntary and they had the full right to withdraw at any stage during the study without any consequences. Participants were informed that their identity would be protected by providing a pseudonym, rather than their actual names.

\subsection{Data Analysis Procedures}

In the current study, the researcher adopted the same steps for analysing the data that are outlined in Creswell's (2014) plan of analysis. This plan involves going through several steps: (1) organizing and preparing data for analysis, (2) reading through all the gathered information in order to acquire a general sense of it, (3) coding the data by detecting text segments and giving a code label to them, (4) representing the data in tables or charts to convey information about each participant, and (5) making an interpretation of the data and comparing the findings with information found in literature (Creswell, 2014).The researcher found this plan very comprehensive and an easy way of dealing with the big amount of raw data gathered. A thematic analysis was utilized in this study, which involved going through all of the following steps: organising, transcribing and coding the data, to extract themes and sub-themes which would represent the findings of this study. Figure 1 is a summary of qualitative data analysis plan which refers to these steps starting from the bottom:

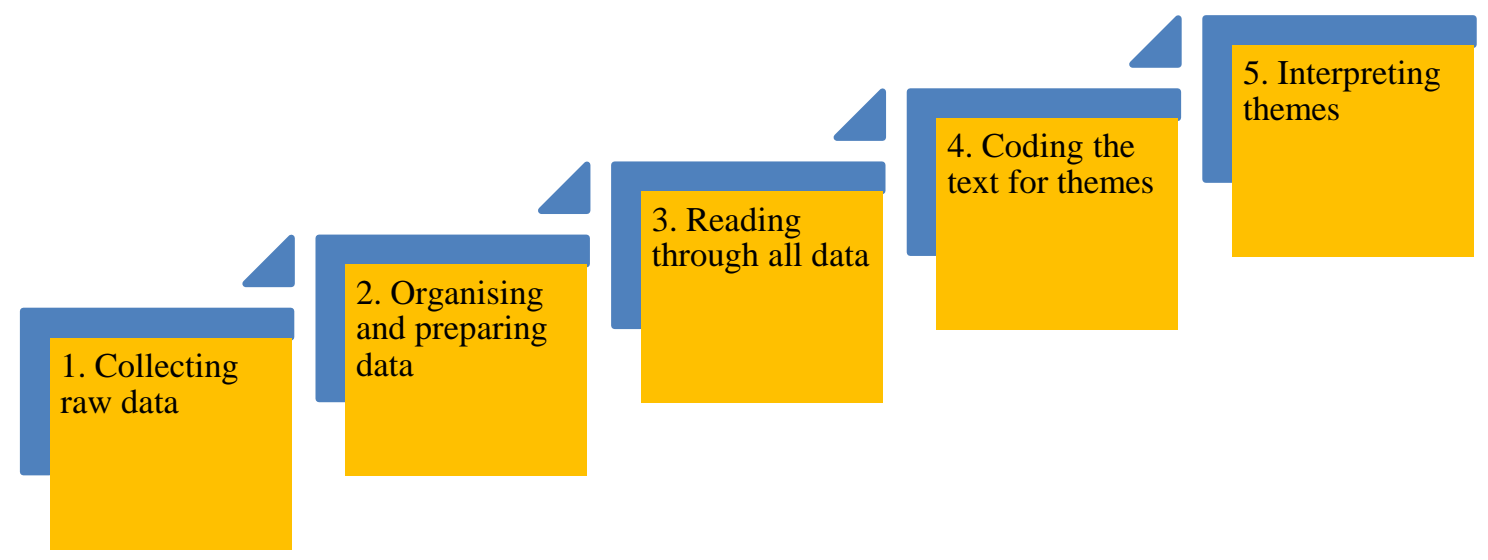

Figure 1: Qualitative Data Analysis Plan, Adapted from Creswell (2014)

\section{Findings}

This section describes the qualitative results that were uncovered through the use of in-depth semi-structured interviews and participant observations. The findings of this study are 
presented in two main sections: 1) general description of the sample, 2) description of the themes and sub-themes.

\subsection{General Description of the Sample}

The sample includes a total of 20 participants, 12 males and 8 females. This study did not intend to make a distinction or a comparison between male and female participants since there was no balanced sample, but rather to get a holistic understanding of the Arabic language maintenance from both genders' views.

Participants in this study came from different Arab countries, including the Middle East and North Africa. Seven were Libyan, six were Iraqi, two were Moroccan, two were Omani, one was Saudi, one was Kuwaiti, and one participant was Emirati. All participants were bilingual speakers of Arabic and English, except for two participants who were multilingual. All the participants in this study were native speakers of Arabic, and Arab in ethnicity.

The participants' demographic information was obtained during the interviews as it is not easy to collect this information with other data collection instruments implemented in this study. This information included gender, age, education, arrival year, occupation, the nationality of the participants and their spouses, and the number of children and languages spoken. These were important variables to be used to determine their impact on language maintenance. Table 1is a summary of the participants' demographics:

Table 1: A snapshot of the participants' demographics

\begin{tabular}{|l|l|l|l|l|l|l|l|l|}
\hline & & & & & \\
\hline
\end{tabular}




\begin{tabular}{|l|l|l|l|l|l|l|l|l|}
\hline & & & & & \\
\hline
\end{tabular}

\subsection{Description of the Themes and Sub-themes}

The analysis of transcripts of both interviews and observations led to the emergence of several themes and sub-themes which contribute to the maintenance of Arabic among the Arabic-speaking community in the regional city of Toowoomba. In this section, the focus is on one theme which refers to the religious status of the Arabic language as an important factor for its maintenance among the Arabic-speaking community.

\subsubsection{Status of the Arabic Language}

The high status of the Arabic language among all Arabs and Muslims contributed effectively to its maintenance and transmission through many generations. All the Arabic-speaking parents shared their thoughts and views about the importance of the Arabic language among the Arabic and Muslim community. Data analysis of all 20 transcripts of interviews revealed that Arabic is the language of the religion and the language of the sacred Qur'an. Their views about the status of the Arabic language are expressed in the following excerpts:

Arabic is the language of Islam. So it is very important because you read the Qur'an in Arabic. (S19F)

The Qur'an has been written and kept in Arabic, and so it will keep Arabic forever. (S2OF)

In the same sense, another participant described Arabic language as being the most commonly spoken languages in the world and also it is the language relates to the people of paradise. The following statement illustrates the participant's views about his language:

Arabic language is very big language; it is a language of the whole Muslim people, this is the language of the holy Quran, it is the language of our religion, it is the language of half 
of the population of this world, and thus the language of "Ahl Al-Janah", "People of the Heaven”. (S8M)

Similarly, another participant indicated that Arabic represents the identity of Islam and all Muslims and Arab communities should learn Arabic to perform their daily prayers as it is the only language of communication when it comes to the establishment of Salat (prayers). The following excerpt expresses the participant's views about the intimate relation between the religion and Arabic:

The identity of Islam was written in Arabic, the Quraan Karim [Sacred Qur'an] is written in Arabic. And when you are going to do Salat [perform prayers] you, you must talk or say what you have to say in Salat by Arabic. So all of that things ah, I think can maintain the Arabic language. Ah, if you need to make a good ah good communication with Allah to get good reward and good benefit for yourself, you should ah understand the language that you need to talk by ah in front of Allah 'Azza WA Jal [God Almighty], you know what I am saying? So, ah at that point every single Muslim, even he is not Arabic, he will try to learn and to understand Arabic to know what he is saying in front of Allah. Yeah, like that I think. (S3M)

In addition to the high status that Arabic holds in Islam, it is also a rich, accurate and strong language that can be used for effective expression, as illustrated in the following statement:

I said it is a complete language, Ah, but the English language is a good language, easy language, but the Arabic is more effective in the expression for the things. Ah, It is more accurate and it is devolved, compared with the English language, this is my own, when you are talking about something, you can describe these things or explain in details, and it is clear and it is better than English actually, grammatically, it is stronger than English that what I think, I think the Arabic language is better than English. (S2M)

The analysis of the interview data revealed that all members of the Arabic-speaking community spoke highly about the close relationship between Islam and Arabic, in which they complete each other in many ways. All participants commented on the high religious status that Arabic holds for being the language of the Holy Qur'an. This theme seemed to be imperative for all the participants as Arabic and Islam are inseparable.

\section{Discussion}

The first observable limitation in this qualitative ethnographic inquiry is related to the generalization of the findings. The aim of this investigation was to explore the experiences and challenges of the Arabic-speaking community rather than to generalize to a larger population. The status of the Arabic language has been found to be crucial in the field of language maintenance, according to several linguists (Clyne, 2005; Baker, 2011; Rouchdy, 2013).

\subsection{Status of Arabic Language}

The status of the Arabic language, either internationally or religiously, has contributed to some extent to the maintenance and transmission of this community language to the second generation children. Hence, the Arabic language has an international status on a global level, especially in terms of the number of the speakers. The language is spoken by over 300 million people and used as by over 1.7 billion Muslims in their liturgical acts (Bale, 2010; Gadri \& Moussaoui, 2015). During the interviews all of the participants spoke about the religious status of their community language. They referred to the Arabic language as a great language for its religious status and in terms of its value for Muslims all over the world. With regards to its religious status, all liturgical actions practiced by Muslims, such as the five daily prayers, must only be performed in the Arabic language. In Toowoomba, this applied not just to the Arabic speakers who know Arabic, but to all Muslims, including Arabs and non-Arabs. This finding is consistent with Rouchdy's (2013) and Hayati and Mashhadi's 
(2010) findings who have reported on Arabic being maintained by Muslim Arabic speakers because of its religious status.

This finding was also supported by Clyne's (2005), Holmes (2013) and Jamai's (2010) research in which it is claimed that Arabic has a high and a privileged position among the Arabic and Muslims speakers. This high position comes from being the language of the Holy Qur'an.

There is no doubt that the religious status of the Arabic language has a significant influence on the Arabic speakers, which culminates in the maintenance of Arabic at a local and national level in Australia. Arabic is among the 10 top maintained languages in Australia (ABS, 2011). It is the second community language after English in Sydney and the second in Toowoomba, after the majority language, English. This research is focused on the religious status of Arabic language rather than its international status because this latter is not always a predictor for language maintenance. The majority of the participants in this study spoke with passion and excitement about the religious status of the Arabic language and they described the intimate relationship between their religion and language.

\section{Conclusion}

The findings of this study suggest that the Arabic language is highly valued by the Arabic speakers in the Queensland city of Toowoomba because of its high exalted status in Islam for being the language of the Qur'an. All the participants in this study spoke with a great passion and excitement about the link between their religion and their language, as they learn the language to maintain their religious identity as Arab Muslims and through the practices of their religion, their Arabic language is well-maintained and preserved.

Thus, the findings related to the maintenance of the Arabic language in the regional city of Toowoomba are of value in enhancing the linguistic and cultural diversity in the Australian context. It may also contribute to the changing multilingual and multicultural structure of Australian society. Moreover, this study is intended to attract linguists' and educators' attention and to stimulate them to place more value on small isolated ethnolinguistic groups in their future research. At a practical level, this research may contribute to Australian multilingualism and multiculturalism by advocating the rights of small immigrant communities to be recognized. 


\section{References}

i. Australian Bureau of Statistics, 2011. Census of population and housing, Canberra: Australian Bureau of Statistics.

ii. Baker, C., 2011. Foundations of bilingual education and bilingualism. 5th ed. USA: Multilingual Matters.

iii. Bale, J., 2010. Arabic as a heritage language in the United States. International Multilingual Research Journal, 4(2), pp. 125-151.

iv. Bateson, M. C., 2003. Arabic language handbook, Washington, D.C: Georgetown University Press.

v. Beeston, A. F. .. L., 2016. The Arabic language today, New York: Routledge.

vi. Benrabah, M., 2004. Language and politics in Algeria. Nationalism and Ethnic Politics, 10(1), pp. 59-78.

vii. Beykont, Z. F., 2010. We should keep what makes us different: Youth reflections on Turkish maintenance in Australia. International journal of the sociology of language, Volume 206, pp. 93-107.

viii. Carreira, M. \& Kagan, O., 2011. The results of the national heritage language survey Implications for teaching, curriculum design, and professional developments. Foreign Language Annals, 44(1), pp. 40-64.

ix. Cavallaro, F., 2005. Language maintenance revisited: An Australian perspective. The Journal of the national association for bilingual education, 29(3), pp. 561-582.

x. Clyne, M., 1991. Community languages. The Australian experience., Sidney: Cambridge University Press..

xi. Clyne, M., 2005. Australia's language potential, Sydney: University of New South Wales Press.

xii. $\quad$ Creswell, J. W., 2014. Research design. Qualitative, quantitative, and mixed methods. 4th ed. Carlifornia: Sage.

xiii. Dweik, B., M. Y Nofal \& Qawasmeh, R. S., 2014. Language use and language attitudes among the Muslim Arabs of Vancouver/ Canada. A sociolinguistic study.. International Journal of Linguistics and Communication, 2(2), pp. 75-99.

xiv. Gadri, S. \& Moussaoui, A., 2015. Arabic texts categorization: Features selection based on the extraction of words' roots. In Computer Science and its Applications, Volume 456, pp. 167-180.

xv. Hatoss, A., 2013. Displacement, language maintenance and identity: Sudanese refugees in Australia. Netherland: John Benjamins Publishing Company.

xvi. Hayati, A. M. \& Mashhadi, A., 2010. Language planning and language-in-education policy in Iran. Language Problems and Language Planning, 34(1), p. 24-42.

xvii. Hijjawi, M. \& Elsheikh, Y., 2015. Arabic language challenges in text based conversational agents compared to the English language. International Journal of Computer Science \& Information Technology, 7(3), pp. 1-13.

xviii. Holmes, J., 2013. An introduction to sociolinguistics. 4th ed. USA: Pearson Education Limited.

xix. Jamai, A., 2008. Language use and maintenance among the Moroccan minority in Britain. [Online] Available at: http://usir.salford.ac.uk

xx. Javed, F., 2013. Arabic and English phonetics. An International Journal in English, 3(1), pp. 113 . 
xxi. Johnson, B. \& Christensen, L., 2012. Educational research: Quantitative,qualitative, and mixed approaches. 4th ed. USA: SAGE Publications.

xxii. Owens, J., 2006. A linguistic history of Arabic, United States: Oxford University Press.

xxiii. Rouchdy, A., 2013. Language conflict and identity. In: A. Rouchdy, ed. Arabic in the American diaspora. New York: RoutledgeCurzon, pp. 133-148.

xxiv. Rubino, A., 2010. Multilingualism in Australia: Reflections on current and future research trends. Australian Review of Applied Linguistics, 33(2), pp. 17.1-17.21.

xxv. $\quad$ Swaan, A. D., 2013. Words of the world: The global language system, UK: John Wiley \&Sons.

xxvi. Vaish, V., 2008. Mother tongues, English, and religion in Singapore. World Englishes, 27(3-4), pp. $450-464$.

xxvii. Versteegh, K., 2014. The Arabic language. 2nd ed. Edinburgh: Edinburgh University Press. 